\title{
Estilos de Professores na Promoção da Motivação Intrínseca: Reformulação e Validação de Instrumento ${ }^{1}$
}

\author{
José Aloyseo Bzuneck² \\ Sueli Édi Rufini Guimarães \\ Universidade Estadual de Londrina
}

\begin{abstract}
RESUMO - A presente pesquisa teve por objetivo avaliar um questionário revisado sobre estilos motivacionais de professores. $\mathrm{O}$ instrumento consiste de oito vinhetas que representam problemas de alunos na escola. Após cada vinheta seguem-se quatro afirmativas a serem marcadas por um adulto numa escala Likert. Cada afirmativa representa uma maneira de o adulto lidar com o problema, num continuum desde uma forma altamente controladora até altamente promotora de autonomia. Responderam aos questionários 1296 professores brasileiros dos ensinos fundamental e médio. Os dados foram submetidos à análise fatorial confirmatória, com base num modelo hipotético de quatro fatores. A análise mostrou que dois de quatro índices revelaram ajustamento adequado dos dados, ao lado de outros dois índices que tiveram ajustamento muito próximo. Desta forma, e considerando-se outros parâmetros, conclui-se que o presente questionário revisado se revela como mais capaz de identificar a estrutura do continuum dos quatro estilos motivacionais.
\end{abstract}

Palavras-chave: estilos motivacionais de professores; orientações de controle versus autonomia; análise fatorial confirmatória; motivação intrínseca.

\section{Teachers' Styles in the Promotion of Intrinsic Motivation: Instrument Revision and Validation}

\begin{abstract}
The aim of the present research was to evaluate a revised questionnaire about teachers' motivational styles. The instrument consists of eight short vignettes describing students problems at school. Following each vignette are four statements to be answered by an adult on a Likert Scale. Each statement represents a manner of the adult dealing with the problem, in a continuum, from highly controlling to highly autonomy supportive. 1296 elementary and secondary Brazilian teachers answered the questionnaires. The data were submitted to a confirmatory factor analysis based on a hypothetical model of four factors. The analysis indicated that two out of four indexes fitted well whereas two others came close to fitting the data. In this way, also considering other parameters, we may conclude that the present revised questionnaire is more capable to identify the continuum structure of the four motivational styles.
\end{abstract}

Key words: teachers motivational styles; control orientation versus autonomy; confirmatory factor analysis; intrinsic motivation.

Ter alunos intrinsecamente motivados no contexto escolar é um sonho acalentado por todo professor que conheça a descrição e as conseqüências desse estado motivacional. Segundo a literatura (ver, por exemplo, Guimarães, 2004; Reeve, Deci \& Ryan, 2004; Ryan \& Deci, 2000b), entendese como intrinsecamente motivado o aluno que realiza as atividades acadêmicas como um fim em si mesmo, ou seja, sem influência de qualquer fator externo, sejam recompensas, pressões, ameaças etc. Em outras palavras, a atividade é valorizada por si mesma, o que inclui um componente afetivo, freqüentemente identificado com interesse. Em conseqüência, esse estado motivacional produz completo envolvimento na tarefa, persistência, concentração intensa, desligamento

1 A presente pesquisa teve apoio financeiro da CNPq concedido ao primeiro autor, pelo Processo n. ${ }^{\circ} 40.1752 / 2003-8$. A segunda autora recebeu apoio financeiro da Fundação Araucária, pelo Protocolo n. ${ }^{\circ}$ 4587.

2 Endereço: Rua Rui Barbosa, 187 J. Tatiani, Londrina, PR, Brasil 86070-610.E-mail: bzuneck@ sercomtel.com.br do tempo e prazer, que Csikszentmihalyi (1992) rotulou de estado de fluir.

Em contraste, e como fenômeno mais comum no contexto escolar, configura-se a motivação extrínseca: quando a pessoa realiza uma ação visando as conseqüências que ela acarreta, ou seja, a ação acontece por influências externas como pressões, recompensas, evitar punições etc. Entretanto, os proponentes da Teoria da Autodeterminação (Reeve \& cols., 2004; Ryan \& Deci, 2000a) sustentam que é inadequado trabalhar apenas com a dicotomia fechada de motivação intrínseca versus extrínseca. Teoricamente, na regulação de qualquer ação intencional, existe uma tendência natural humana para internalizar regras, pressões e valores externos. Assim, exceto na desmotivação, que é definida como ausência de intenção para agir, prevê-se um continuum de internalização das regulações externas, que progressivamente passa por quatro tipos de motivação extrínseca, chegando à motivação intrínseca, condição de total controle pessoal da origem da ação. Por sua vez, esta condição motivacional apresenta-se com uma graduação da regulação que vai desde uma regulação totalmente externa, passando pela regulação introjetada, depois 
pela identificada, chegando por fim à regulação integrada. Esta última forma de auto-regulação da motivação extrínseca aproxima-se muito da própria motivação intrínseca em seu grau de autodeterminação, mas não coincide com ela, já que na regulação integrada o que sustenta a realização da atividade é a sua importância para a obtenção de metas e valores internalizados pela pessoa. Em contrapartida, na motivação intrínseca o interesse pessoal está na atividade em si mesma, estando inserido o componente de interesse e de prazer.

A Teoria da Autodeterminação (Deci \& Ryan, 1985; Reeve \& cols., 2004; Ryan \& Deci, 2002) identificou os processos cognitivos pelos quais fatores ambientais afetam a motivação intrínseca. Isto é, os comportamentos serão intrinsecamente motivados na medida em que, em função de influências sociocontextuais, forem atendidas três necessidades básicas do ser humano: de competência, de autonomia e de vínculo ou relacionamento. No presente contexto, será focalizado apenas o componente de autonomia e como ela pode ser implementada na escola. Brevemente, existirá senso de autonomia, crucial à motivação intrínseca, quando a pessoa se perceber como origem de suas ações, ou seja, com locus interno de causalidade (deCharms, 1984). Por outro lado, quando um aluno perceber que seus comportamentos ocorrem apenas por influência de agentes externos com seus controles, pressões, recompensas externas etc. (isto é, quando houver percepção de locus externo de causalidade), não terá experiência de autodeterminação e, portanto, não se pode dizer que esteja intrinsecamente motivado. Pesquisas têm comprovado essas associações (Pelletier, Fortier, Vallerand \& Brière, 2001; Ryan \& Deci, 2000b; Ryan \& Stiller, 1991). Reeve (1998), em particular, focalizou o tópico de como preparar futuros professores para adotarem estilos motivacionais não controladores.

Como o demonstraram Ryan e Deci (2006) e Chirkov, Ryan, Kim e Kaplan (2003), esse conceito de autonomia não deve ser confundido com independência nem com individualismo mas refere-se à percepção pessoal sobre a origem da ação. Além disso, Chirkov e cols. (2003) concluíram em seu estudo que autonomia é entendida da mesma forma em culturas diversas, ou seja, na definição operacional aqui adotada, esse termo não tem um significado funcional apenas em determinadas culturas ocidentais, como se poderia argüir.

Em suma, tanto a teoria como os dados de pesquisa sugerem que as formas de motivação autodeterminadas, assim como a própria motivação intrínseca, dependem positivamente de comportamentos interpessoais caracterizados como promotores da autonomia. Em outras palavras, o estilo motivacional adotado pelos educadores responde acentuadamente pelo tipo de motivação do aluno, consideradas as variações acima descritas.

Entretanto, uma outra ala de estudiosos interessou-se especificamente pela mensuração dos diversos estilos adotados por professores. Como pioneiros dessa vertente, no início dos anos 1980, Edward Deci e colaboradores (Deci, Schwartz, Sheinman \& Ryan, 1981), desenvolveram um questionário denominado Problems in Schools, que se tornou referencial para outras pesquisas como as de Flink,
Boggiano e Barrett (1990), Guay, Boggiano e Vallerand (2001), Reeve, Bolt e Cai (1999), entre outros.

Segundo os criadores do questionário Problems in Schools (Deci \& cols., 1981), podem ser identificados nos professores dois estilos motivacionais básicos opostos: o promotor de autonomia e o controlador. Os 32 itens do instrumento foram elaborados para avaliar esses dois estilos e, adicionalmente, os dois níveis intermediários de moderadamente promotor de autonomia e moderadamente controlador. Propunha-se, portanto, avaliar o estilo motivacional do professor por meio dessas quatro variáveis: $\mathrm{AC}$ (estilo altamente controlador), MC (moderadamente controlador), MA (moderadamente promotor de autonomia) e AA (altamente promotor de autonomia). Descrição detalhada do formato do questionário será apresentada mais adiante.

No Brasil, Guimarães, Bzuneck e Boruchovitch (2003) descreveram em detalhes o desenvolvimento de uma versão do questionário de Deci e cols. (1981) para o nosso idioma e a aplicaram a uma grande amostra de professores e professoras de vários estados da União. O objetivo do estudo era verificar as propriedades psicométricas desse instrumento em nosso meio, para uso posterior em pesquisas e em programas de intervenção. A análise fatorial exploratória identificou, com propriedades psicométricas definidas, quatro fatores subjacentes aos itens e que em parte correspondiam aos quatro estilos motivacionais mencionados. Entretanto, as análises trouxeram à tona problemas, sendo alguns deles já apontados na literatura (por ex., Reeve \& cols., 1999).

Primeiro, nem todos os itens da versão brasileira do questionário carregaram suficientemente em qualquer fator e outros carregaram de modo igual em dois ou mais fatores. Houve casos em que, mesmo carregando num determinado fator, pareceu ambígua essa relação, considerado o significado aparente do item. Por isso, dos 32 itens originais, apenas 24 foram conservados nas análises finais. Mas surgiu outro problema, relativo à identificação conceitual de pelo menos um dos fatores. Os estilos motivacionais AA e AC apareceram como claramente correspondentes aos fatores 2 e 4 , respectivamente. O fator 3 poderia ser considerado como compatível com um estilo intermediário entre AA e AC e não apenas como promotor moderado de controle, na suposição original de Deci e cols. (1981). Porém, os itens que carregaram no fator 1 , que corresponderia ao estilo moderadamente promotor de autonomia, não se revelaram como representativos dessa variável. A interpretação mais coerente é que tais itens se referem apenas a comparação social, um significado psicológico aparentemente distinto do estilo moderadamente promotor de autonomia que se supunha representar. Portanto, a escala original, pelo menos em sua versão brasileira, contém itens e uma estrutura fatorial que não corresponde de forma inequívoca aos constructos preconizados pela teoria. Adicionalmente, um outro problema foi que a correlação entre os escores entre AA e AC foi praticamente nula $(r=0,03)$, quando se esperavam valores negativos altos, considerando-se que representam estilos motivacionais diametralmente opostos.

Esses resultados inspiraram o presente estudo, cuja relevância está apoiada em três importantes razões. Primeiro, era necessário, mediante uma reelaboração e criação de itens, superar as inconsistências e inadequações do ques- 
tionário inicial elaborado por Deci e cols. (1981) e aplicado no nosso contexto. Procedimento dessa natureza tem sido preconizado na literatura (ver, por ex., Burnett \& Dart, 1997; Reise, Waller \& Comrey, 2000) como condição para se assegurar as propriedades psicométricas aceitáveis da respectiva escala. Uma segunda razão, ligada à anterior, advém da importância de se investigar em que grau o questionário Problems in Schools, agora com as alterações propostas, funcionaria como medida de quatro tipos de comportamentos promotores de autonomia ou controle com suas variações intermediárias. Em outras palavras, questiona-se se o continuum da proposta teórica original reflete-se em modalidades comportamentais discerníveis por meio de suas respectivas subescalas.

Em terceiro lugar, a avaliação dos estilos motivacionais dos professores tem relação com as práticas educacionais em sala de aula. Com o objetivo de motivar seus alunos ou de lidar com problemas de motivação em classe, os professores aplicam seus conhecimentos e crenças pessoais pertinentes e, como conseqüência, tendem a desenvolver determinados hábitos comportamentais. Conhecimentos e crenças são estruturas de pensamento ou representações cognitivas que podem ser acessadas e manifestadas em auto-relatos, desde que haja uma estimulação específica, por exemplo, mediante questionários (Pintrich, 2000). Daí a relevância de se dispor de instrumentos válidos e fidedignos de medida do que os professores sabem ou acreditam em relação à motivação. Levantar esses estilos motivacionais é condição imprescindível para orientação, intervenção e treinamento tanto de professores em serviço como daqueles que se formam para o ensino. Em outras palavras, em relação a professores ou futuros professores que almejem ter alunos não simplesmente motivados por força de controladores externos, mas socializados para a motivação autônoma, de qualidade superior, é preciso partir da identificação de sua atual base de conhecimentos e de suas crenças acerca de estratégias promotoras da motivação (Nolen \& Nicholls, 1994).

Em suma, com tais justificativas em mente, o objetivo da presente pesquisa foi determinar a fidedignidade e a validade de um novo questionário psicométrico desenvolvido para medir quatro possíveis estilos motivacionais de professores. Mais especificamente, buscou-se com este estudo:

1) Desenvolver novos itens no questionário original, relativos às variáveis que apresentaram inconsistências ou inadequações na sua formulação original e na experiência brasileira acima descrita.

2) Levantar as propriedades psicométricas do novo instrumento por meio de análise fatorial confirmatória.

\section{Método}

\section{Participantes}

A amostra consistiu de 1296 professores(as) dos ensinos fundamental e médio de cidades da Bahia, Rio de Janeiro, Mato Grosso do Sul, São Paulo, Paraná, Santa Catarina e Rio Grande do Sul. Nenhum dos componentes desta amostra havia participado do estudo anterior de Guimarães e cols. (2003). A idade dos participantes oscilou desde 22 anos até acima de 50. Da mesma forma, variou consideravelmente o tempo de serviço no ensino, além de estar representado um grupo de professores que, embora formados, ainda não atuavam em classe. Dados os objetivos da pesquisa, todos os participantes foram considerados como uma amostra única.

\section{Procedimentos: coleta de dados}

A aplicação do instrumento ocorreu, cidade por cidade e ao longo de vários meses, por ocasião de cursos de pósgraduação ou de formação continuada de que participavam os(as) professores(as). Por ocasião da exposição dos objetivos da pesquisa, foi explicitado que a participação era voluntária e sem identificação pessoal. Os protocolos preenchidos corresponderam aos que deram sua concordância formal, em cumprimento das exigências éticas legais. Na maioria das vezes, um ou outro dos próprios autores do estudo ministrava pessoalmente os questionários nas salas de aula, de modo coletivo. Em poucos casos, contou-se com auxílio voluntário de colaboradores treinados que se deslocaram para as respectivas cidades para alguma atividade acadêmica. $\mathrm{O}$ tempo gasto na atividade girou em torno de 15 minutos.

\section{Desenvolvimento do questionário}

O instrumento original de Deci e cols. (1981), denominado Problems in Schools, retomado por Guimarães e cols. (2003), consistia de uma escala tipo Likert a ser marcada a propósito de oito vinhetas que descrevem cenários comuns às salas de aula, em que um aluno ou aluna apresenta algum problema como baixo esforço, comportamentos anti-sociais, retraimento e furto. A título de exemplo, segue-se uma das vinhetas com alternativas a serem marcadas.

Luís é um aluno médio, com desempenho no nível de sua classe. Entretanto, nas duas últimas semanas, ele parece desatento, apático e não tem participado do grupo de leitura. O trabalho que faz é bem feito, mas ele não tem completado as tarefas. Uma conversa pelo telefone com a mãe dele não trouxe informações úteis. A coisa mais apropriada para a professora de Luís fazer é:

a) acentuar para ele a importância de terminar suas tarefas porque ele precisa aprender esse conteúdo para o seu próprio bem;

b) informá-lo de que ele não precisa terminar todo o trabalho e verificar se ela pode ajudá-lo a descobrir a causa;

c) fazê-lo ficar depois da aula até o dia em que as tarefas sejam completadas;

d) levá-lo a se comparar com os colegas no que diz respeito à realização das tarefas encorajá-lo a alcançá-los.

Os quatro itens acima haviam sido elaborados para representarem, aleatoriamente, os quatro estilos motivacionais baseados na teoria, ou seja, a) moderadamente controlador, b) altamente promotor de autonomia, c) altamente controlador e d) moderadamente promotor de autonomia. Para as demais sete vinhetas seguiam-se outras quatro alternativas condizentes com o cenário e igualmente representativas dos quatro estilos motivacionais. Cada uma das quatro alternativas após 
as vinhetas devia ser marcada pelo participante numa escala de 1 a 7, conforme julgasse o grau de propriedade expressa na solução nele contida, desde muito impróprio até muito apropriado. Portanto, ao participante caberia marcar nas subescalas um total de 32 itens, produto de quatro itens para cada uma das oito vinhetas.

Como os resultados das análises conduzidas no estudo brasileiro anterior (Guimarães \& cols, 2003) haviam levantado problemas na configuração de quatro fatores ortogonais, em função de determinados itens, uma primeira decisão consistiu na elaboração pelos autores deste estudo, com base na literatura e espelhando-se nos conceitos da teoria, de alguns novos itens relativos a cada variável do continuum dos estilos motivacionais: 1) estilo altamente controlador (AC); 2) moderadamente controlador (MC); 3) moderadamente promotor da autonomia (MA) e 4) altamente promotor de autonomia (AA). Para cada item original com alguma inadequação foram criados quatro novos, dentre os quais foi escolhido aquele que fosse avaliado como mais representativo daquela variável. Três juizes, pesquisadores da área, realizaram o trabalho de seleção e validação de conteúdo dos novos itens a serem incorporados na escala.

Assim, em relação aos itens originais representativos de estilo altamente controlador (AC), concluiu-se que, em cada um de três cenários, um item deveria ser mais incisivo, com redação menos sujeita a ambigüidades no nosso contexto. Assim, na vinheta acima apresentada como exemplo, a alternativa c) original foi substituída por esta outra, considerada mais representativa de orientação altamente controladora: Nunca permitir que ele saia da sala de aula enquanto não tiver terminado as tarefas solicitadas.

A respeito do estilo moderadamente controlador (MC), também em três vinhetas criaram-se itens novos. Por exemplo, na vinheta 4, o item b) ficou assim: Lembrá-lo de que todos esperam que ele se saia bem na escola e, caso ele não abra mão do jogo para estudar, irá se sentir mal.

Os oito itens relativos ao estilo que se apresentava como moderadamente promotor de autonomia (MA) apareciam, na versão anterior, como mais problemáticos pelo seu conteúdo explícito de comparação social. Por esse motivo, foram elaborados, pelo mesmo critério seletivo já descrito, oito novos itens que representassem uma forma de motivar correspondente ao rótulo e ao conceito teórico dessa variável. Assim, por exemplo, o item d) após a primeira vinheta passou a ter a seguinte redação: Contar para ele que, quando tinha sua idade, também não conseguia entender a importância das aulas e tarefas; mais tarde entendeu e teve que estudar mais para recuperar o tempo perdido.
Por último, entre os itens representativos da variável estilo promotor de autonomia (AA), apenas o item b), após a primeira vinheta, ganhou nova redação, mais explicitamente concordante com o rótulo: Conversar com ele sobre como ele percebe a escola e sobre quais são os motivos que o levaram a diminuir seu interesse pelas atividades de aprendizagem.

Em síntese, 16 itens do questionário original receberam nova redação: três na variável de alto controle (AC); quatro, na de moderado controle (MC); todos os oito da variável moderada autonomia (MA) e um em alta autonomia (AA). Os itens novos podem ser vistos na Figura 1.

Uma vez concluída, a versão do questionário com todos os novos itens foi aplicada, a título de estudo piloto, a 10 professoras que não fizeram parte da amostra final. Assim que preencheram o questionário, foram entrevistadas sobre aspectos redacionais da escala. Após a análise dos protocolos das entrevistas, que ocasionou pequenos retoques, chegou-se à consolidação do questionário.

\section{Procedimentos estatísticos}

Uma estatística descritiva revela a distribuição dos valores dos itens pelos fatores, como se pode ver na Tabela 1. Há uma tendência de simetria e com valores reduzidos e significativos da curtose. Esses dados, obtidos por meio do questionário revisado descrito, foram então submetidos à Análise Fatorial Confirmatória, para o que se fez uso do pacote eletrônico Statistica. Esse tipo de análise tem por objetivo testar hipóteses sobre uma estrutura pré-definida existente nos dados e os resultados da aplicação da técnica podem indicar se a estrutura é ou não aceitável para explicar o comportamento dos dados. Em outras palavras, os procedimentos desta análise servem para se avaliar a validade de construto das medidas (Artes, 1998; Floyd \& Widaman, 1995). Burnett e Dart (1997), juntamente com Reise e cols. (2000), acrescentam que essa análise pode ser usada por ocasião de modificação e de desenvolvimento de escalas, como é o presente caso. Assim, uma estrutura de $n$ fatores, hipotética, será testada para se concluir se ela tem características de um modelo ajustado e em que medida se concretiza o ajustamento.

Por isso, uma exigência primeira para o uso da análise fatorial confirmatória é que se especifique um modelo com determinado número de fatores subjacentes aos dados, bem como quais variáveis recaem em cada fator (Floyd \& Widaman, 1995; Reise \& cols., 2000). No presente caso, essa condição foi atendida, com base tanto na teoria como nos dados obtidos pela aplicação da versão brasileira anterior (Guimarães \& cols., 2003), submetidos à análise fatorial

Tabela 1. Estatística descritiva dos escores dos itens em cada fator, correspondente a cada estilo motivacional, com os índices de assimetria e de curtose.

\begin{tabular}{|c|c|c|c|c|c|c|c|}
\hline Variável & $N$ & Média & Mínimo & Máximo & Desvio Padrão & Assimetria & Curtose \\
\hline Alt. Control. & 1258 & 2,72 & 1,00 & 7,00 & 1,00 & 0,58 & $-0,13$ \\
\hline Mod. Control, & 1267 & 4,19 & 1,00 & 7,00 & 1,07 & $-0,05$ & $-0,40$ \\
\hline Mod. Auton. & 1268 & 5,28 & 1,25 & 7,00 & 0,88 & $-0,45$ & 0,36 \\
\hline Alt. Auton. & 1247 & 6,00 & 1,50 & 7,00 & 0,73 & $-1,01$ & 1,77 \\
\hline
\end{tabular}


exploratória. Mas, como lembra Cronbach (1996), existe uma infinidade de modelos hipotéticos a serem testados e os resultados da análise não garantem que um determinado modelo pré-especificado seja o melhor, embora indique o seu ajuste aos dados observados. Por isso, sempre é oportuno testar um modelo alternativo.

No presente caso, dois modelos foram submetidos à análise. O Modelo 1, em que se trabalhou com a hipótese de quatro fatores, correspondentes aos quatro pontos do continuиm, conforme a teoria. Alternativamente, foi também testado um Modelo 2, composto de apenas três fatores hipotéticos, em que as duas variáveis intermediárias (MA e MC) comporiam apenas uma.

Entre os procedimentos, foi aqui empregada a estimativa de probabilidade máxima, mais utilizada e recomendada nos casos em que os dados são multivariados, normalmente distribuídos e a amostra é suficientemente grande (Floyd \& Widaman, 1995), condições bem atendidas neste estudo. A qualidade de ajustamento de cada modelo foi avaliada mediante a extração dos cinco seguintes índices (tem sido recomendada a utilização de pelo menos quatro), com a exigência de que as estimativas de parâmetro se situem dentro de variações aceitáveis (Burnett \& Dart, 1997; Floyd \& Widaman, 1995; Kline, 1994): 1) o $\chi^{2}$, embora seja uma distribuição considerada demais sensível a pequenos desvios do modelo quando a amostra é bastante grande (Finch \& West, 1997); 2) a razão do $\chi^{2}$ dividido pelos graus de liberdade; 3 ) o índice da qualidade do ajustamento (goodness of fit index - GFI, de Joreskog); 4) o índice ajustado da qualidade do ajustamento (adjusted goodness of fit index - AGFI de Joreskog); 5) o erro de aproximação (root mean square error of approximation - RMSEA, de Steiger-Lind). De acordo com a literatura (Burnett \& Dart, 1997; Kline, 1994), se o $\chi^{2}$ for significativo deve-se concluir por um ajustamento pobre do modelo. No caso do $\chi^{2}$ dividido pelos graus de liberdade, $o$ resultado deve ser preferencialmente menor que 2 , embora alguns autores admitam um teto de até 5 (por exemplo, Vassend \& Skrondal, 1999). O GFI e o AGFI devem atingir um valor de 0,90 ou mais para serem aceitáveis. Já o RMSEA não deve ultrapassar 0,5 para que seja considerado ótimo o nível de ajustamento, embora a faixa entre 0,6 e 0,8 aponte para um ajustamento adequado (Finch \& West, 1997).

\section{Resultados}

Os resultados da análise fatorial confirmatória para o Modelo 1, com quatro fatores por hipótese, indicaram um ajustamento aceitável. O índice pelo $\chi^{2}$ absoluto apresentou um valor de 2058,32 significativo $(p=0,00)$, o que faz descartar um ajustamento exato. Como Bentler (1990) aponta, porém, a maioria dos pesquisadores não adota esse tipo de índice, utilizando outros, desde que satisfatórios. Assim, a razão $\chi^{2} / 458$ graus de liberdade foi de 4,49 , um valor aceitável segundo alguns autores (Vassend \& Skrondal, 1999). O índice da qualidade do ajustamento $(\mathrm{GFI}=0,895)$ e o índice ajustado (AGFI $=0,879$ ) apareceram como muito próximos do valor crítico. O erro de aproximação (RMSEA) foi de 0,05 . A consistência interna pelo $\alpha$ de Cronbach entre os oito itens de cada uma das quatro subescalas foi o seguinte: para o estilo altamente controlador (AC), $\alpha=0,71$; para o estilo moderadamente controlador (MC), $\alpha=0,72$; para o estilo moderadamente promotor de autonomia (MA), $\alpha=0,66$ e, por último, para o estilo altamente promotor de autonomia (AA), $\alpha=0,65$. Observe-se que, em qualquer desses casos, a solução de se excluir qualquer item não resultaria em aumento do valor do $\alpha$. A correlação entre os fatores aparece na Tabela 2, bem como na Figura 1. Observe-se na Figura 1 que, para cada fator, os valores dos coeficientes de determinação foram satisfatórios e variaram, no caso do fator latente AC, de 0,37

Tabela 2. Correlações de Pearson entre os escores dos itens nos quatro fatores.

\begin{tabular}{|c|c|c|c|c|}
\hline & $\mathrm{AC}$ & MC & MA & $\mathbf{A A}$ \\
\hline Alt. Controlador (AC) & & $0,66^{* *}$ & $0,37 * *$ & 0,02 \\
\hline Mod .Controlador (MC) & & & $0,58 * *$ & $0,17 * *$ \\
\hline Mod. Autonomia (MA) & & & & $0,48^{* *}$ \\
\hline Alt. Autonomia (AA) & & & & \\
\hline
\end{tabular}

$* * p=0,01$

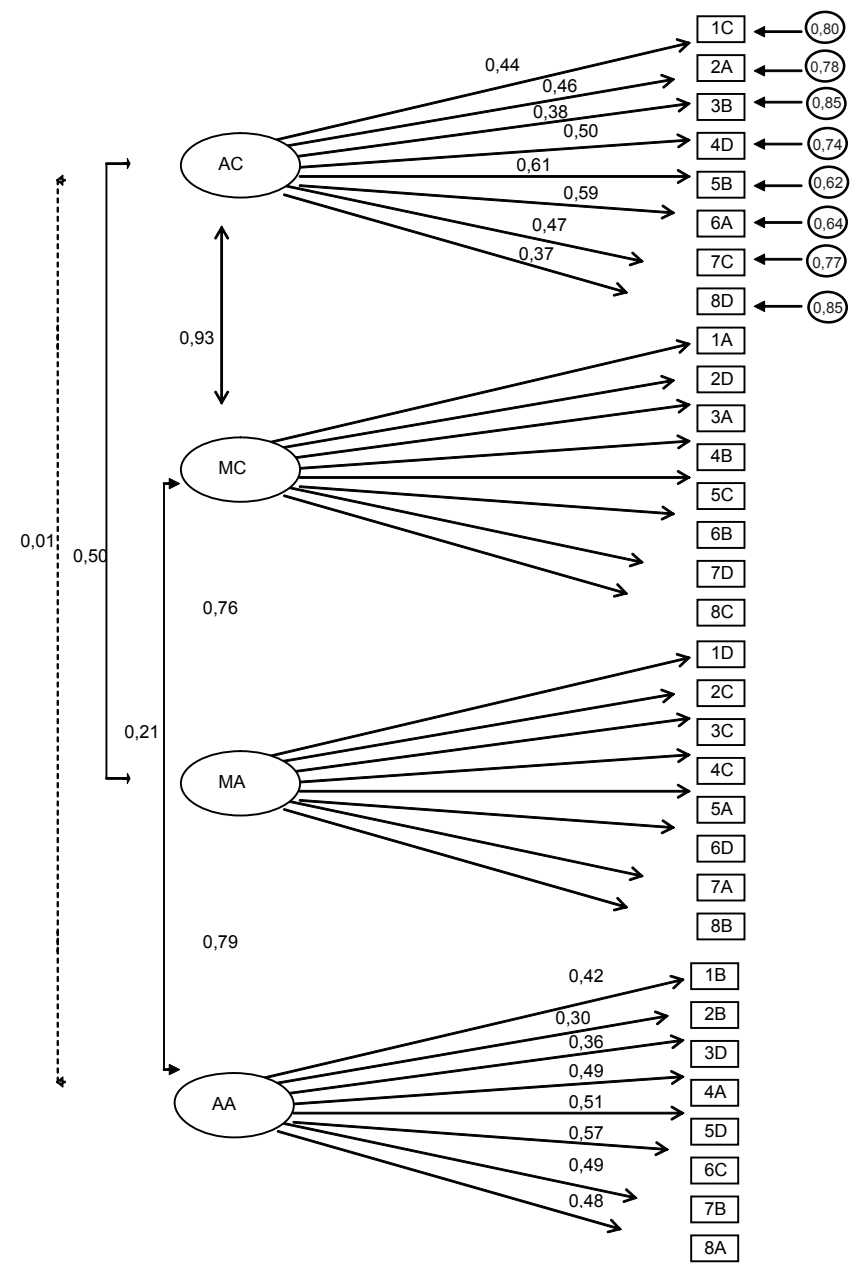

Figura 1. Modelo final de quatro fatores, correspondentes aos elementos do continuum de autodeterminação. As elipses representam os fatores latentes; os retângulos, as variáveis observadas; e os círculos, os erros residuais. As linhas contínuas das setas representam correlações significativas e as secionadas, correlação não significativa. 
a 0,61; do fator MC, entre 0,35 e 0,56; no fator MA, entre 0,37 e 0,51 ; e no fator AA, entre 0,30 e 0,57 . Portanto, podese concluir que cada fator latente prediz adequadamente os comportamentos das variáveis observadas.

Já o Modelo 2, que considerava apenas três fatores como hipótese, apresentou resultados algo diferentes. $\mathrm{O}$ $\chi^{2}=7918,878$ foi também significativo $(p=0,00)$. Porém, a proporção $\chi^{2} / 496$ graus de liberdade resultou num valor alto de 15,96 . O GFI foi de 0,869 e o AGEF foi de 0,850 , ambos menos próximos do valor crítico do que no Modelo 1. Apenas o RMSEA atingiu um valor aceitável de 0,06. Brevemente, no Modelo 2 verifica-se um ajustamento mais pobre que o Modelo 1.

\section{Discussão}

O presente estudo pretendeu descobrir se os quatro graus do continuum de estilos motivacionais, propostos teórica e empiricamente por Deci e cols. (1981), podem ser considerados construtos distintos, capazes de serem identificados por meio de instrumento de mensuração com características de fidedignidade e validade. Com esse objetivo, foi aplicada a análise fatorial confirmatória aos dados obtidos com um questionário reformulado, no qual foram introduzidos novos itens em relação a um questionário original, traduzido e aplicado em nosso meio. A amostra à qual foi aplicado o novo instrumento foi numerosa e, adicionalmente, representativa de várias regiões do país, o que contribui para o fortalecimento da validade externa dos construtos levantados.

Os resultados das análises estatísticas favorecem a manutenção do continuum de quatro estilos motivacionais proposto por Deci e cols. (1981), igualmente contemplado em estudos como o de Reeve e cols. (1999) e Guimarães e cols. (2003). No presente estudo, apareceram como inadequados os índices de ajustamento do modelo hipotético com apenas três fatores (Modelo 2). Já entre os diversos índices de ajustamento do Modelo hipotético 1, dois apresentaram-se com valores que atenderam plenamente às exigências desse tipo de análise, ao lado de outros dois com valores muito próximos do valor mínimo exigido. Além disso, foram satisfatórios os valores dos coeficientes de determinação, expressos pela carga de cada item em seu respectivo fator latente, ou seja, cada fator latente prediz adequadamente prediz adequadamente a variância observada. Em outras palavras, o grau em que cada item ou variável carrega em cada fator apareceu definido de forma inequívoca, levando à conclusão de que as questões apresentadas no questionário correspondem a cada um dos quatro estilos motivacionais propostos teoricamente.

Verificou-se, de modo especial, que os oito itens ou variáveis criados para substituírem os da versão original agora se coadunam com o fator denominado estilo moderadamente autônomo (MA), o que leva à conclusão de que o presente instrumento possibilitou, neste particular, a superação de um problema de fatoração encontrado na primeira versão de Guimarães e cols. (2003). Portanto, essa subescala em particular, com seus novos itens, apresenta-se com propriedades psicométricas aceitáveis, em comparação com o questionário anterior utilizado por esses autores.
Adicionalmente, as correlações encontradas entre os quatro fatores confirmam a estrutura teórica do modelo. Entre os extremos do continuum dos estilos motivacionais que são o estilo altamente controlador e o altamente promotor de autonomia, a correlação é nula, ou seja, trata-se de construtos independentes. Ou seja, uma coisa é o professor ser altamente promotor de autonomia, outra coisa é ser altamente controlador. Isto, porém, não significa que se trata de estilos mutuamente excludentes, podendo ambos encontrar-se na mesma pessoa e aparecer diferenciadamente em cada situação. Neste caso, confirma-se o resultado estatístico encontrado por Guimarães e cols. (2003). Da mesma forma, os estilos intermediários aproximam-se de seus respectivos extremos (isto é, MC com $\mathrm{AC}$; MA com AA) e entre si esses intermediários se relacionam proximamente. Esses resultados devem ser considerados em relação ao próprio formato do questionário que, por decisão dos autores originais (Deci \& cols., 1981), contém vinhetas de conteúdo diversificado, que representam situações hipotéticas de diversas da escola. Tal variedade de situações permite uma varredura mais autêntica de algumas situações escolares e, em cada caso, os professores podem responder de modo mais ou menos controlador ou mais ou menos promotor de autonomia.

Em síntese, com base nas análises dos dados levantados neste estudo, podem considerar-se como satisfatórias as propriedades psicométricas do novo instrumento, aceitandose esse modelo de quatro fatores ou estilos motivacionais, preferível ao modelo alternativo com apenas três fatores. Daí que este novo questionário já poderia ser convenientemente usado por pesquisadores interessados em investigar esses tipos de construtos em professores. Os resultados abrirão espaço para programas de intervenção, quando se pretender tornar os alunos intrinsecamente motivados ou mais auto-regulados.

Não se pode, porém, concluir que o novo questionário ora descrito e analisado não careça de aperfeiçoamento. Os indicadores de consistência interna entre os itens das duas subescalas de estilo altamente e de moderadamente promotores de autonomia estão um pouco abaixo do mínimo aceitável. Vários itens apresentaram-se com carga fatorial minimamente aceitável. Isso aponta para se tentarem novos itens em novas pesquisas, um procedimento de todo previsível quando se trata de avaliação de construtos psicológicos.

Segundo Reise e cols. (2000), os procedimentos da análise fatorial confirmatória parecem funcionar melhor quando a estrutura fatorial é limpa, simples, ou seja, uma estrutura em que cada item carrega altamente em um e apenas um fator. Este é um objetivo a ser buscado em novos estudos com o presente questionário. Ao mesmo tempo, porém, há que se reconhecer uma dificuldade inerente a esse tipo de conteúdos. Como lembram esses mesmos autores, a propósito de escalas de personalidade, as medidas têm limitações em atender a esse critério de parcimônia, dada a complexidade de determinados construtos. Ora, é bem estabelecido como são complexos os processos motivacionais dos alunos e sua relação com aspectos do ambiente que os afetam. Embora bem avançados, não se pode ainda concluir que os estudos nessa área sejam definitivos, em 
particular quando se trata daqueles que focalizam a criação e a validação de instrumentos de medida.

\section{Referências}

Artes, R. (1998). Aspectos estatísticos da análise fatorial de escalas de avaliação. Revista de Psiquiatria Clínica, 25, 223-228.

Bentler, P. M. (1990). Comparative fit indices in structural models. Psychological Bulletin, 107, 239-246.

Burnett, P. C. \& Dart, B. C. (1997). Conventional versus confirmatory factor analysis: Methods for validating the structure of existing scales. Journal of Research and Development in Education, 30, 126-132.

Chirkov, V., Ryan, R. M., Kim, Y. \& Kaplan, U. (2003). Differentiating Autonomy From Individualism and Independence: A SelfDetermination Theory Perspective on Internalization of Cultural Orientation and Well-Being. Journal of Personality and Social Psychology, 84(1), 97-110.

Cronbach, L. J. (1996) Fundamentos da testagem psicológica. Porto Alegre: Artes Médicas.

Csikszentmihalyi, M. (1992). A Psicologia da Felicidade. São Paulo: Saraiva.

deCharms, R. (1984). Motivation enhancement in educational settings. Em R. Ames \& C. Ames (Orgs.), Research on motivation in education: Student motivation (pp. 275-310). New York: Academic Press.

Deci, E. L. \& Ryan, R. M. (1985). Intrinsic motivation and selfdetermination in human behavior. New York: Plenum.

Deci, E. L., Schwartz, A. J, Sheinman, L. \& Ryan, R. M. (1981).An instrument to assess adults' orientations toward control versus autonomy with children: reflections on intrinsic motivation and perceived competence. Journal of Educational Psychology, 73 (5), 642-650.

Finch, J. F. \& West, S. G. (1997). The investigation of personality structure: Statistical models. Journal of Research in Personality, 31, 439-485.

Flink, C., Boggiano, A. K. \& Barrett, M. (1990). Controlling teaching strategies: undermining children's self-determination and performance. Journal of Personality and Social Psychology, 59, 916-924.

Floyd, F. J. \& Widaman, K. F. (1995). Factor Analysis in the Development and Refinenment of Clinical Assessment Instruments. Psychological Assessment, 7, 286-299.

Guay, F., Boggiano, A. K. \& Vallerand, R. J. (2001). Autonomy support, intrinsic motivation, and perceived competence: conceptual and empirical linkages. Personality and Social Psychology Bulletin, 27, 643-650.

Guimarães, S. É. R. (2004). Motivação intrínseca, extrínseca e o uso de recompensas em sala de aula. Em E. Boruchovitch \& J. A. Bzuneck (Orgs.), A motivação do aluno: Contribuições da psicologia contemporânea (pp. 37-57). Petrópolis: Ed. Vozes.

Guimarães, S. É. R., Bzuneck, J. A. \& Boruchovitch, E. (2003). Estilos motivacionais de professores: Avaliação de um instrumento de avaliação. Psicologia: Teoria e Pesquisa, 19, 17-24.
Kline, P. (1994). An easy guide to factor analysis. New York: Routledge.

Nolen, S. B. \& Nicholls, J. G. (1994). A place to begin (again) in research on student motivation: Teachers' beliefs. Teaching and Teacher Education, 10, 57-69.

Pelletier, L. G., Fortier, M. S., Vallerand, R. J. \& Brière, N. M. (2001). Associations among perceived autonomy support, forms of self-regulation, and persistence: A prospective study. Motivation and Emotion, 25, 279-306.

Pintrich, P. R. (2000). An achievement goal theory perspective on issues in motivation terminology, theory, and research. Contemporary Educational Psychology, 25, 92-104.

Reeve, J. (1998). Autonomy support as an interpersonal motivating style: is it teachable? Contemporary Educational Psychology, 23, 312-330.

Reeve, J., Deci, E. L. \& Ryan, R. M. (2004). Self-determination theory. A dialectical framework for understand sociocultural influences on student motivation. Em D. M. McInerney \& S. Van Etten (Orgs.), Big theories revisited (pp. 31-60). Connecticut: Information Age Publishing.

Reeve, J., Bolt, E. \& Cai, Y. (1999). Autonomy supportive teachers: How they teach and motivate students. Journal of Educational Psychology, 91, 537-548.

Reise, S. P., Waller, N. G. \& Comrey, A. L. (2000). Factor Analysis and Scale Revision. Psychological Assessment, 12, p. $287-$ 197.

Ryan, R. M. \& Deci, E. L. (2002). Overview of self-determination theory: An organismic dialectical perspective. Em E. L. Deci \& R. M. Ryan (Orgs.), Handbook of self-determination research (pp. 3-33). Rochester: University of Rochester Press.

Ryan, R. M. \& Deci, E. L. (2006). Self-Regulation and the Problem of Human Autonomy: Does Psychology Need Choice, SelfDetermination, and Will? Journal of Personality, 74, 15571585 .

Ryan, R. M. \& Deci, E. L. (2000a). Intrinsic and extrinsic motivations: Classic definitions and new directions. Contemporary Educational Psychology, 25, 54 -67.

Ryan, R. M. \& Deci, E. L. (2000b). Self-determination theory and the facilitation of intrinsic motivation, social development, and well-being. American Psychologist, 55, 68 -78.

Ryan, R. M. \& Stiller, J. (1991). The social contexts of internalization: Parent and teacher influences on autonomy, motivation, and learning. Em P. R. Pintrich e M.L. Maehr (Orgs.), Advances in motivation and achievement: Vol. 7. Goals and self-regulatory processes (pp. 115-149). Greenwich: JAI Press.

Vassend, O. \& Skrondal, A. (1999). The problem of structural indeterminacy in multidimensional symptom report instruments. The case of SCL-90-R. Behaviour Research and Therapy, 37, 685-701.

Recebido em 01.02.2006

Primeira decisão editorial em 26.03.2006

Versão final em 30.05.2007

Aceito em 20.06.2007 


\section{INTERESSADO EM AGILIZAR A PUBLICAÇÃO DE SEU ARTIGO?}

\section{Informações e dicas para os autores sobre aspectos operacionais}

\section{O manuscrito é reencaminhado pelo autor em versão reformulada}

Quando a versão reformulada é aceita e são poucos os reparos, as correções necessárias são feitas na secretaria da revista. Com a versão atualizada em formato eletrônico, o processamento pode ser imediatamente iniciado. Na falta destas informações, não é possível o processamento de correções nem a preparação do manuscrito para editoração. Em suma, atraso para entrar no prelo.

\section{Informações e dicas para os autores com artigos no prelo}

\section{O manuscrito é encaminhado para editoração}

No caso de o manuscrito ser aceito para publicação, é esperada a participação do autor no processo de preparação do artigo na fase de editoração. A primeira prova do artigo, editada a partir da versão em disquete ou CD-R, é enviada para exame ao(s) autor(es). O prazo para devolução é de 48 horas. A obediência ao prazo permite a manutenção da composição prevista para o volume/número da revista. O atraso no envio da prova examinada pode implicar em mudanças na composição de um número no prelo. E pode resultar em atraso na edição final. 